\title{
Dilemmas in Palliation
}

\author{
Deepak Gupta \\ Wayne State University/Detroit Medical Center, \\ USA
}

\section{Introduction}

The term 'palliation' by Latin origin meaning 'cloaking' (Stolberg, 2007) of symptoms of disease would seem to be most relevant at the end-of-life. However, palliation by essence does not preclude the use of 'cloaking' at other time-points of disease management, wherein a pallaitive approach may provide deep insight into realistic goals of medicine and consequently result in long-lasting changes in individual patient care. Additionally the dilemmas in applying the essence of the palliative care model to the art of medicine as a whole may lead to substandard medical care out of ignorance. The present chapter will attempt to cover some of the different aspects/dilemmas in palliation from this author's perspective.

\section{Dilemmas}

\subsection{Palliative care diagnoses}

Since the advent of the concept of modern palliative care in the United Kingdom (Saunders, 2002), palliation services have primarily covered cancer and cancer-related diagnoses because cancer was supposedly considered to be a terminal illness with the only difference being the speed of progression of various cancers. Slowly with time, other medical diagnoses with similar clinical profiles of variable progression but eventual terminal endpoint found their desirable places in palliative medical care (Addington-Hall \& Higginson, 2001, as cited in Weatherall, 2001). Paradoxically, the improved survivorship of the cancer patients perpetrated the need of delayed palliation for these cancer patients. So the big question is which all medical diagnoses need palliation as part of their ongoing medical care when death is ultimate truth of all life and irrespective of any medical diagnosis, all patient populations may require palliative services at different time points in their medical lives.

Let us try to understand this with a clinical scenario. When this author proposed for inclusion of moribund obesity as a palliative care diagnosis in the medical literature (Gupta, 2009), this author had variable responses from the medical community. This author's perspective for this inclusion was based on the chronicity of this disease as well as its terminal outcome with variable rate of progression. However, the medical community needs to understand that the inclusion of a medical diagnosis under the spectrum of palliation does not mean the end of the road for the patients suffering from that particular disease. Rather the inclusion is meant to target those patient populations who will be in dire 
need of palliative services in due course of time; and the underlying intent for these inclusions will be patient advocacy for better quality of life instead of quantity of life. The early recognition of palliative care needs in a patient population does not mean the preclusion of curative medical care because palliation is not synonymous with the end-oflife care but is a model based on the realization and following of realistic goals and outcomes by both patient and medical team at any given time-point of patient care.

In summary, all medical diagnoses except acute and spontaneously resolving diseases or acute and completely curable diseases without any long-lasting sequelae can be included in the palliative care diagnoses' spectrum.

\subsection{Disease stage and introduction to palliation}

The next big question is related to the appropriate timing for the introduction of palliation in any disease state. The palliation as a concept can be instilled in the medical care as soon as it is recognized that the disease state will be running a chronic course that will require psychological, social and spiritual care besides the attempts at curative physical care. The dilemma is that based on the present understanding of the society about the palliative care, the early introduction of palliation model will confuse the patients, their families and the medical caregivers about the appropriateness of palliation. However, the answer does not lie in deterring the palliation till the very-end-of-life. Instead pioneering an education and awareness initiative for both patient population as well as medical community to realize the role of palliation in almost all disease stages will establish achievable prudent holistic care.

Let us try to understand this with a clinical scenario. It is always amazing that the focus of present medical care is on the innumerable attempts at curing the not-so-curable diseases and in turn providing false hope of longevity without paying attention to the adequacy of quality of these long lives. Peripheral vascular diseases are widespread medical phenomenon with the progressively worsening epidemics of morbid obesity and unrelenting cigarette smoking. As the primary involvement of the lower limbs with deteriorating symptoms usually bring the patients with the hope of curative surgeries to save the dying lower limbs, the limbs that are dying at variable rates of progression or are already dead undergo staged revascularizations that fail requiring staged resections. Though these lines of management may appear to be curative to both patients and medical caregivers, however, this has palliation written all over it as the underlying disease with non-resolving modifiable risk factors cannot be undone and in time, the formal transfers to palliative services are ascertained by the medical teams when there is no more dead limb to be saved. It may be easy for palliative care advocates to propose that the patient needed an early review of the patient's medical goals and needs in regards to helplessly trying to maintain a painless lower limb without actually losing it; however when the end of the limb is inevitable and the goal of revascularizing a dying limb becomes almost analogous to attempting the revascularization of dead bowel, it is already delayed dawning on the medical caregiver team that although the limbs do not have as much length as bowel that can be harmlessly resected, the end of all types of tissues require identically appropriate communication of palliative considerations for adjusted goals and achievable outcomes so that no one loses the perspective for effective patient care. 
In summary, the stage of the disease does not matter for efficient enrollment of the patient for palliative care services; however, this will require the mass awareness programs to impress upon the patient and caregiver (family and medical) populations alike that although the palliation has its origin as a specialty to tender services to the abandoned patient populations at their end-of-lives, the palliation has enough potential to mature into a consulting, educating and caregiver specialty rendering the black-and-white medical care along with a good coverage of the gray zones in the patient care needs.

\subsection{Interaction of curative and palliative care teams}

The modern medicine has become so sophisticated that the complexities of patient care provisions cannot be accomplished without adequate compartmentalization of the medical care into specialty and sub-specialty care. However, this specialist based care model is bound to fail without sound and constant interdisciplinary discussions and interactions for a common goal of good quality holistic care. This becomes more cumbersome when palliative services are branded as subspecialty catering a very small proportion of the patients who are in dying stages even though palliation as a medical concept is continually practiced across the spectrum of all medical specialties without clear-cut perception of the irony in their 'curative' medical care.

Let us try to understand this with a clinical scenario. When on professional palliative care providers' initiative the liberal use of the opioids for pain management became one of the pillars stones of the modern patient care, the medical society was skeptical that high doses of the opioids may hasten patient's death by their sedative and respiratory depressant effects. However, the semi-centennial experience of the modern palliative medicine affirms that early institution of palliative care can actually prolong life, minimally but by definite amounts (Bourseau 2011; Temel et al. 2010). If this is the unexpected transformation of the palliative ideology, this author does not see any harm in this ideology's analogous application for all inexplicably incurable diseases where medication based symptomatic management ensures patients to live longer with delayed complications of lesser severities. The examples include and are not limited to diabetes mellitus and hypertension. Herein, the primary care physicians including primary specialists caring for the patients' special medical needs can come on level grounds with the palliative care teams who can guide and educate them and their patients based on the long experience of palliation in understanding the societal fears and concerns about the agonies related to the dying and the uncertainty related to the dreams of a peaceful death whenever it happens.

Let us try to understand this with another perspective. This author proposed that whenever the true potential of a medical diagnosis since its inception entails the long term prognosis of a patient ending up in the laps of palliative care teams, it is the humane duty of the medical care providers to realize the potential of preemptive palliation (Gupta 2010a) as a resourceful involvement and input of the palliative care teams for making patients understand that early involvement of the palliation in their medical care is analogously nothing more than the provision of advance care directives or living will that are a common place in present day medical care. The early inclusion (and not exclusion) of palliative care team in the patient care will enhance the patient care with palliative care teams' experiences in regards to enormous evidence based understanding of patients' goals when they are 
dealing with a lifelong suffering secondary to their unrelenting chronic diseases. This inclusion at early stages of diseases will relieve a major burden from other medical teams because they may not be well experienced in dealing with the complex questions of "why

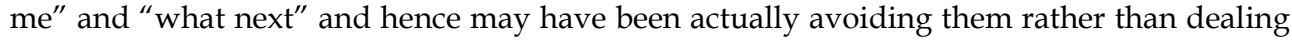
with them by including the experts for these apparently trivial but still complex clinical scenarios. This author propose that if the word 'palliation' itself interferes with the deserved inclusion of palliative services at so-early stages in the medical care, then for the sake of surrendering to the complacent society, the palliation can be offered at all patients under the disguised name of 'supportive care' that will still maintain the essence and experience of the palliation for a complete holistic patient care.

In summary, it is not at all about the timely transition of medical care from curative to palliative ideology but it is about sharing the patient care between the medical teams who are working to cure the diseases and the palliative care teams who help patients understand how to live with their diseases.

\subsection{Curative needs at the end-of-life}

This discussion now leads us to the reciprocity of the clinical scenario at the end of life where the patients have now become the complete responsibility of palliative care teams and are almost abandoned by their primary care providers with minimal if any involvement of their primary specialists. This understandable abandonment secondary to 'nothing more to offer' reasoning may leave the palliative care teams unwary to the curative needs of their patients at their end of lives. The palliative care teams may not be hesitant in asking for second opinions for the acute and curable diseases of their patients even if it involve the short term but best possible specialist care at that point of time. The lists of such scenarios may be short but definitely include the broad spectrum and bug-specific antibiotics for difficult infections, interventional angioembolizations of the acute bleeders that may be very acutely hastening the death, curative amputations of dead and septic limbs, short term ventilator support for acute but resolvable pneumonias and the possible percutaneous coronary revascularization in the event of the acute transmural myocardial infarction.

Let us try to understand this ambiguity with a clinical scenario. The patient is suffering at the end of life waiting for inevitable death. Though the body has advanced stages incurable and terminal disease, the tissues are susceptible to common bacterial attacks. These infectious diseases may become difficult secondary to the underlying advanced stage illness and hence requiring advanced generation antibiotics for resistant organisms. The dilemma is whether to hold those expensive antibiotics and avoid their likely adverse effects in a frail body or to provide the known cure for these infections that may have definite improvement in quality of life with possible prolongation of life. In due course, if it is the septic limb that is the source of this difficult infection, the curative amputation may be the best possible medical decision for prolonged life. The pain and symptoms associated with curable pneumonias and unanticipated acute myocardial infarction in an otherwise healthy heart must have the possibility considered by their palliative teams for consultations and management by the intensivists and cardiologists.

In summary, the patient management at the end-of-life by palliative care teams not only involves the symptomatic care but also the aggressive counter-action to the acute but potentially distressing ailments with all potential resources of curing them if there is a 
feasible and efficient cure available for the ailment at that point of time. In other words, the combined and shared team approach of curative and palliative care teams all through the course of disease is essential to maintain a dignified medical care for the patients since the inception of the disease process till the peaceful end of life.

\subsection{Patient's choices or family's wishes}

Patient autonomy is integral part of modern medicine and especially palliative care medicine because in the present form of palliation, a lot of decisions are related to negotiating a cost-effective medical care without prolonging a life that is poor in quality. The definite and transparent patient autonomy can only be exercised when the patients make some future decision in regards to their medical care like in advance care directives at a point of life when they are hail and healthy. Even though during these advance decisions documentation all possible clinical scenarios are brought up for clear cut discussions about the patient's destiny, still these scenarios are figments of patient's future and the patients may decide differently when these clinical scenarios become a reality of their lives. At such point of times of reality, the patients' autonomous decisions are certain to be colored with their fears, their love-hate relationship with their family and the uncertainties of the medicine. This level of uncertainty in autonomous medical decision-making becomes more complex when the family has to act as a surrogate decision maker for the patients who become incompetent secondary to their terminal illnesses.

Let us try to understand this ambiguity in patient autonomy with a clinical scenario. In the zeal of their healthy times and as a proponent of the total control on their body, life and death, the advance care directives are documented. However, as the life evolves, the medical science advances and the personal life experiences and observations of surrounding death accumulates, the documenter's perspectives may change and become completely opposite to the documented wishes. Moreover, when the time comes for making the end-of-life decisions, the emotional status of the sufferer is clouded by 'why me' that may not allow the sufferer an appropriate amount of time to understand the inevitability of the ensuing dying and death or to peacefully accept the turn of events in his life that brought the patient to this terminal event. Additionally, the families may not agree with the decisions made by the patients whether they are vocal or subtle about their own preferences in regards to the turn of events. Eventually, the mental status changes in all the patients rendering them incompetent at the very end-of-life; and all final decisions are to made by the families or surrogates who if emotionally attached to their patients cannot escape the coloring of their decisions based on their love-hate emotions for the patients and if emotionally detached to their patients cannot be acting more than a legal writer for the consent that allows the patients in question to die within a pre-decided time-frame after the withdrawal/withholding of life-sustaining treatments.

In summary, the care for the families and emotionally attached surrogates is integrated in the art of modern palliative medicine because the palliative medicine is not only meant to care for the dying but the survivors of deaths in the family; however, it will be a misnomer when we accrue medical decision-making of the patients as autonomous because the families and surrogates covertly or overtly influence in the medical decision making of and for the patients. 


\subsection{Patient's choice to embrace death NOW}

The intent to restore total control over their lives and extending that control to end the life at the time pre-determined by the patient is one big controversial and debatable topic in modern medical science. The reasons may differ why the terminally ill patients may decide that why wait for death to embrace them when they can embrace the death at their own preferential times. The legal and ethical system does not endorse this ideology because their understanding is that the modern palliative medicine can overcome the patients' fears of loss of control over their terminal symptoms by effective and aggressive palliation. Still a very few states respect persons' decisions to end their lives at their own free will and practice euthanasia and/or physician assisted suicide including Netherlands, Belgium, Luxembourg, and Oregon (United States) and Washington (United States); as well as Switzerland as a state allowing assisted suicide only if the executor does not have selfish motivations to assist suicide. This very small percentage of global community practicing the debatable palliative concept may represent the analogous very small percent of terminal patients who if given the opportunity, will decisively complete their wishes for death despite aggressive palliative support.

Let us try to understand this debate with a clinical scenario. At the time of diagnosis of their terminal disease, the patients decide to end their lives because of their poor understanding of the disease and its terminal symptoms and the failure of medical care teams to pursue timely efficacious discussions about their diseases. As the disease evolves, the patient understands their diseases and the supportive care offered and rendered by the palliative care teams; and at this point of time, they may decide that this may be the right time to take the final flight at their own leisure because they feel that it may be the right thing to do. However, eventually, the patient despite attempting to sell their thought for dying at their chosen time ends up losing their full competence or control on their mental status; and are left at the mercy of their family or surrogate decision maker to decide for what they have beem asking all the time: timely death. Additionally, even though the surrogate decision making endorses the withdrawing and withholding the life-sustaining treatments as terminal palliative management protocols, however, instead of the pre-determined times by the patients' choices, now the death is happening when the surrogates and medical teams based on their understanding and perception of the progressive terminal disease decides to let go the patient.

In summary, if the time of flight and the time to embracing the death can be determined by the medical futility and difficult but allowed surrogate decision making, constantly debating the euthanasia or physician assisted suicide may be unnecessarily delaying the appropriate incorporation of these concepts in the armamentarium of modern day palliative care practitioners; this may be ironic when the modern medicine holds patient autonomy in such high regards and pledges to uphold it under all circumstances.

\subsection{Choices and cost to the society}

The evolution of the medicine has been an uphill task and the new heights to scale keep becoming more tedious with stringent hardships involved. In historical times, the rewards for the practice of medicine by the practitioners was the job satisfaction involved with the 
patient care with secondary gains involving better hierarchical position in the society with or without financial gains. However, with the increased sophistication and the complexities of the diseases and their management involving the soaring costs of the research for new medicines to continually ensure sound medical care under the fear of the litigating patient population has increased the financial burden of maintaining health. These costs are directly or indirectly bore by the productive sections of the population even though it may appear that the government or the insurance companies are paying for it. Therefore when a poor person decides to surrender to death believing that there is no accesible hope against the terminal disease in the circumstances of personal poverty, this personal choice is no different than a case of an insured person whose timely death happens under the circumstances of the surrogate decision making that withholds or withdraws the costly but medically futile life sustaining treatments. The medical costs are contained either by the patients' personal choices or the family's/society's surrogate choices because the quality of life matters more than the quantity of life, and the decision makers realize that the survivors with very poor quality of life accrue financial as well as non-financial costs for the patients, families and the societies.

In summary, the direct and indirect cost-bearing and cost-sharing of palliation guide many decisions in the palliative care scenarios and the guilt and/or the grudge for the inability to appropriately provide for medical care with or without palliation to a patient should not prevent the patient, the family or the society to decide for the most cost-effective medical solutions for the patient's terminal illness.

\section{Innovative perspectives}

\subsection{Pre-emptive palliation}

This goes without saying that palliation is not terminal care. Similarly, the encompassing of some preventive case scenarios or pre-emptive care scenarios under the cloak of palliation is not ambitious overreaching efforts on the part of the palliative care provider community. The only proposition by the proponents of palliative care model is that the medical care team realizes the abovementioned facts and incorporates the ideologies of the palliative teams when they care for their patients since the inception of the diagnosed diseases. Recognizing the palliative virtues of the diseases, risk factors, treatment plans and prognosis of the diseases treated by non-palliative care teams will go a long way in ensuring the thorough understanding of the disease and the realistic expectations about the management with specific answers for patients' fears related to the disease prognoses. Pre-emptive palliation is the concept of initiating these early interventions in all non-palliative care practitioners' settings so that patients can gain from the abundance of knowledge and experience of the palliative care teams which they purport to share and educate for the direct and indirect care of the potential patients who may need traditional end of life care in future. One good example can be the regular and non-hesitant deliverance of Life is a Gift talk as proposed by this author (Gupta, 2010a) for all the potential patients who are identified during their hospital stays or recurring emergency room visits as at-risk population unresponsive to non-pro-active life style discussions that are affecting the prognoses of their diseases and interfering their appropriate, timely and efficacious medical care. 


\section{2 'Considering' do-not-resuscitate}

The life span of a human life keeps growing with advanced medical practices and development of new and sophisticated life-sustaining treatments. The ratio of the productive life span to the total life span keeps decreasing even though the total numbers of both productive and total life span years keep increasing. The life span as a species has been growing with contributing evolutionary factors like grandmother hypothesis (not grandfather hypothesis) effect (Lahdenperä et al. 2004, 2007, 2011) as well as technological factors like improved medical care; however, the quality of this increased life span may be scarred by the cultural factors like alienating family constituents and psychological factors like loneliness and abandonment. The lonely long-living controlling human being has the responsibility by choice and by reason to choose for the end of life decisions and document in the ways best known to human society including family if any, friends if any, attorneys if any, family physicians if any or imprinted on their body parts as tattoo flash as suggested by this author (Gupta 2010b) so that even though the people may die alone but the consent, the choice and the control at the final moments will be theirs that has already been communicated to the caregiver team in multiple and variable ways. At the end, it is the people's choice and people's say in their times of death that are endorsed, followed and executed by the people surrounding them including medical and non-medical caregiver teams based on the system devised as per the cultural, social, ethical and legal standards.

\subsection{Paradox of slippery slope}

Debate for and against euthanasia and assisted suicide at the end of life is analogous to the hot debate between the pro-lifers and pro-choicers at the beginning of life; the only differences being that though the fetus in question has no say in these decisions, the society is almost equally divided in their propositions for two different types of fate for them; however, the terminally ill population, who can have insight and understanding to make the choices regarding end of life conditions, are deemed unfit to choose death over life in almost $98 \%$ countries of the world and many of these societies who do not allow euthanasia or assisted suicide accept withdrawal and withholding life sustaining treatments at such point of times when the terminal patients can no longer decide on their own and the family and society decide based on their perceptions of what the patient would have decided under the conditions of the medical futility of their conditions. There is always a big concern for endorsing the death-by-choice in regards to association of slippery slope to it; however, there is no single ideology (dominant or oppositional) where the society does not reach a slippery slope when it is critically overdone leading to counter-productivity because of a lack of the dialogue between the antagonizing ideologies. The only variation in the incidence of slippery slope with any ideology is the lag time in achieving the critical breakpoint and subsequent tripping to slippery slope. Additionally, when ideologies obsessively highlight the slippery slope of their oppositions, they suffer the paradox of the slippery slope secondary to over-zealously even so ignorantly or arrogantly overlooking their own approaching critical break-points to slip. The only possible answer is continuity in a dialogue between the supposedly antagonizing ideologies when they may be actually two sides of the same coin to decide for each clinical case scenario on case-by-case basis. The important thing for the conflicting ideologies is to share the pedestal and work in the best interests of the patients', families' and societies' choices, dignities and duties. It took long 
time for palliation to be accepted as a patient care specialty when the dominant ideology of curing the diseases was at its peak and ended up overdoing the search for 'cures' by enrolling the terminal patients to non-salvageable treatments and non-curative lifesustaining methods. Similarly, the time may have come for the palliation to remember its hardships as a clinical ideology in infancy and henceforth, share some of its newly-found recognition in the society with the advocates of euthanasia and assisted suicide because there is always enough space for all types of ideologies to survive and flourish as long as they do not go overboard their critical points for slippery slope. The understanding of paradox of slippery slope for conscientiously accepting modality of death may not be as difficult to understand as it appears because in the analogous social scenarios, brain dead patients undergo organ harvesting for living through the fellow human beings even when few question if brain dead are actually 'dead' (Banja, 2009), and convicted felons on death row are executed by lethal injections when the civilized society recognizes that their lives pose more risk to fellow human beings than their deaths to human civilization.

\section{Conclusion}

In summary, per this author (Gupta, 2008), we die in the system we create; and it is not about right to live or right to die but the best negotiable ideology for each individual case scenario to render the most appropriate medical care for the patient in question by maintaining an open-ended continuous dialogue among the conflicting medical ideologies that prevents and/or resolves the dilemmas for the medical care providers and avoids the confusion in the patients, families and societies. Whether it is inclusion of new palliative care diagnoses, pre-emptive palliation, considering do-not-resuscitate directives or societal acceptance for euthanasia/assisted suicide, palliation provides a perfect floatation for a patient to achieve a state of seamless flying in their living, in their dying and into their death above the rocky mountains of pain and despair associated with chronic diseases, advanced stages, unrelenting end-of-life symptoms and terminal state of life.

\section{Acknowledgment}

This author is deeply indebted to the inspirational mentors, Sushma Bhatnagar, MD, and Seema Mishra, MD, Institute Rotary Cancer Hospital, All India Institute of Medical Sciences, India as well as Michael Stellini, MD, and Harold Michael Marsh, MBBS, Wayne State University/Detroit Medical Center, United States.

\section{References}

Banja, J.D. (2009). Are brain dead patients really dead? The Journal of Head Trauma Rehabilitation, Vol.24, No.2, (March-April 2009), pp. 141-4, ISSN 0885-9701

Bourseau, M. (2011). Early access to palliative treatment prolongs life. Revue de l'infirmière, No.168, (February 2011), pp.33-4, ISSN 1293-8505

Gupta, D. (2008). We will die in the system we create. Journal of Palliative Medicine, Vol.11, No.8, (October 2008), pp. 1155, ISSN 1096-6218

Gupta, D. (2009). Moribund obesity as a palliative care diagnosis. Journal of Palliative Medicine, Vol.12, No.6, (June 2009), pp. 515-516, ISSN 1096-6218 
Gupta, D. (2010)."Life is a gift": a vision for preemptive palliation. Journal of Palliative Medicine, Vol.13, No.2, (February 2010), pp. 109, ISSN 1096-6218

Gupta, D. (2010). Tattoo flash: consider "do not resuscitate". Journal of Palliative Medicine, Vol.13, No.9, (September 2010), pp. 1155-1156, ISSN 1096-6218

Lahdenperä, M.; Lummaa, V.; Helle, S.; Tremblay, M. \& Russell, A.F. (2004).Fitness benefits of prolonged post-reproductive lifespan in women. Nature, Vol.428, No.6979, (March 2004), pp.178-181, ISSN 0028-0836

Lahdenperä, M.; Russell, A.F. \& Lummaa, V. (2007). Selection for long lifespan in men: benefits of grandfathering? Proceedings. Biological Sciences/ The Royal Society, Vol.274, No.1624, (October 2007), pp.2437-44, ISSN 0962-8452

Lahdenperä, M.; Lummaa, V. \& Russell, A.F. (2011). Selection on male longevity in a monogamous human population: late-life survival brings no additional grandchildren. Journal of Evolutionary Biology, Vol.24, No.5, (May 2011), pp.1053-63, ISSN 1010-061X

Saunders, C. (2002). Hospice: a global network. Journal of the Royal Society of Medicine, Vo.95, No.9, (September 2002), pp.468, ISSN 0141-0768

Stolberg, M. (2007). "Cura palliativa". The concept of palliative care in pre-modern medicine (c. 1500-1850). Medizinhistorisches Journal, Vol.42, No.1, (2007), pp.7-29, ISSN 00258431

Temel, J.S.; Greer, J.A.; Muzikansky, A.; Gallagher, E.R.; Admane, S.; Jackson, V.A.; Dahlin, C.M.; Blinderman, C.D.; Jacobsen, J.; Pirl, W.F.; Billings, J.A. \& Lynch, T.J. (2010). Early palliative care for patients with metastatic non-small-cell lung cancer. The New England Journal of Medicine, Vol.363, No.8, (August 2010), pp.733-742, ISSN 0028-4793

Weatherall, D.J. (2001). Palliative care for non-cancer patients. Journal of the Royal Society of Medicine, Vo.94, No.11, (November 2001), pp.600-601, ISSN 0141-0768 


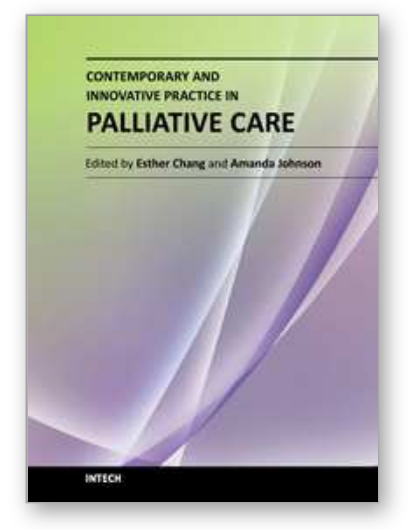

\author{
Contemporary and Innovative Practice in Palliative Care \\ Edited by Prof. Esther Chang
}

ISBN 978-953-307-986-8

Hard cover, 302 pages

Publisher InTech

Published online 10, February, 2012

Published in print edition February, 2012

This book is designed to provide a comprehensive insight unto the key and most prevalent contemporary issues associated with palliation. The reader will find viewpoints that are challenging and sometimes discerning, but at the same time motivating and thought-provoking in the care of persons requiring palliation. This book is divided into three sections. Section 1 examines contemporary practice; Section 2 looks at the challenges in practice; Section 3 discusses models of care. This book is an excellent resource for students, practising clinicians and academics. By reading the book, reflecting on the issues, challenges and opportunities ahead, we hope it will create within the reader a passion to take on, explore and further develop their palliative care practice.

\title{
How to reference
}

In order to correctly reference this scholarly work, feel free to copy and paste the following:

Deepak Gupta (2012). Dilemmas in Palliation, Contemporary and Innovative Practice in Palliative Care, Prof. Esther Chang (Ed.), ISBN: 978-953-307-986-8, InTech, Available from:

http://www.intechopen.com/books/contemporary-and-innovative-practice-in-palliative-care/dilemmas-inpalliation

\section{INTECH}

open science | open minds

\author{
InTech Europe \\ University Campus STeP Ri \\ Slavka Krautzeka 83/A \\ 51000 Rijeka, Croatia \\ Phone: +385 (51) 770447 \\ Fax: +385 (51) 686166 \\ www.intechopen.com
}

\author{
InTech China \\ Unit 405, Office Block, Hotel Equatorial Shanghai \\ No.65, Yan An Road (West), Shanghai, 200040, China \\ 中国上海市延安西路65号上海国际贵都大饭店办公楼405单元 \\ Phone: +86-21-62489820 \\ Fax: +86-21-62489821
}


(C) 2012 The Author(s). Licensee IntechOpen. This is an open access article distributed under the terms of the Creative Commons Attribution 3.0 License, which permits unrestricted use, distribution, and reproduction in any medium, provided the original work is properly cited. 